\title{
Source of Mineralization Material of Xiaochigou Gold Deposit in Western Henan: Sulfur and Lead Isotope Geochemistry
}

\author{
Liu Zhenghua ${ }^{1,2,{ }^{*}, \text { Luo Zhengzhuan }}{ }^{1,3}$, Li Tianyuan², Li Zenghui ${ }^{2}$, Bao Wentong ${ }^{4}$ \\ ${ }^{1}$ Henan Nonferrous Mineral Exploration Engineering Research Center, Zhengzhou, China \\ ${ }^{2}$ No.6 Geological Team of Henan Province Nonferrous Metals Geological Mineral Resources Bureau, Zhengzhou, China \\ ${ }^{3}$ Henan Nonferrous Metals Geological Exploration Institute, Zhengzhou, China \\ ${ }^{4}$ No.7 Geological Team of Henan Province Nonferrous Metals Geological Mineral Resources Bureau, Zhengzhou, China
}

Email address:

1049746587@qq.com (Liu Zhenghua)

${ }^{*}$ Corresponding author

\section{To cite this article:}

Liu Zhenghua, Luo Zhengzhuan, Li Tianyuan, Li Zenghui, Bao Wentong. Source of Mineralization Material of Xiaochigou Gold Deposit in Western Henan: Sulfur and Lead Isotope Geochemistry. International Journal of Mineral Processing and Extractive Metallurgy.

Vol. 4, No. 4, 2019, pp. 58-63. doi: 10.11648/j.ijmpem.20190404.11

Received: August 15, 2019; Accepted: September 21, 2019; Published: January 10, 2020

\begin{abstract}
Xiaochigou Gold Deposit is located in the middle of Xiongershan metamorphic core complex in Qinling orogenic belt. Based on the analysis of sulfur and lead isotopes in altered rock type ores formed in the main metallogenic stage of the deposit, it is found that the $\delta^{34} \mathrm{~S}$ of sulfur isotope of the deposit is between-3.05\% and $10.93 \%$, mostly remaining within the range of meteorite sulfur, indicating that the sulfur mainly comes from the mantle with the addition of crustal sulfur, which reflects the sulfur isotopic composition of mantle sulfur after being mixed with crustal materials. The lead isotope ${ }^{206} \mathrm{~Pb} /{ }^{204} \mathrm{~Pb}$ value is $17.09-17.53,{ }^{207} \mathrm{~Pb} /{ }^{204} \mathrm{~Pb}$ value is $15.31-15.61$, and ${ }^{208} \mathrm{~Pb} /{ }^{204} \mathrm{~Pb}$ value is $37.20-38.10$. The variation range is not wide, belonging to normal lead range. Lead isotopic characteristic parameters and related diagrams show that the lead in ores has crust-mantle mixing characteristics. The sulfur and lead isotope compositions show that the ore-forming materials of the deposit are mainly mantle-derived materials, and the deep mantle-derived materials are mixed with crust-derived materials.
\end{abstract}

Keywords: Xiaochigou Gold Deposit, Sulfur and Lead Isotope, Isotopic Composition, Isotopic Geochemistry, Metallogenic Material Source

\section{Introduction}

The Xiaochigou gold deposit in Henan Province is located in the north of the thrust-fold belt on the northern margin of the Qinling orogenic belt, the middle part of the Xiongershan metamorphic core complex, and the north-eastern end of the Qiliping-Xingxingyin regional fault. It is a medium-sized vein-like high-grade gold deposit discovered in the early 1990s. At present, the deposit is facing the dilemma that shallow mining has been basically mined out and deep prospecting is becoming more and more difficult. In this case, it is necessary to further summarize the metallogenic regularity, explore the genesis of the deposit, establish prospecting model and guide its deep prospecting. The predecessors have done some research on the spatial distribution of ore bodies and prospecting prospects in deep part of the deposit [1-2]. However, there is no report on the source of ore-forming materials of the Xiaochigou gold deposit, and many studies have been done on the adjacent deposits. Shanggong gold deposit and Ganshu gold deposit are two typical deposits, which are identical with Xiaochigou gold deposit. They are all structural altered rock type gold deposits, and the three deposits are located in Qiliping-Xingxingyin regional fault zone.

There are different understandings about the genesis of Shanggong gold deposit. Some scholars [3-6] consider that the Taihua Chao Group, Xiong'er Group and Huashan Complex are the source of ore-forming materials on the basis of isotope studies. Among them, the Taihua Chao Group is regarded as the primary source bed and the Xiong'er Group as 
the derived source bed; Some scholars [7, 8] believe that the complexity of water-rock interaction makes isotope studies impossible to trace the source of ore-forming materials and fluids in orogenic gold deposits, especially to distinguish metamorphic and magmatic fluids; Chen Yanjing and other scholars [9, 10] considered that the Guandaokou Group-Luanchuan Group strata on the southern side of the Machaoying fault were the only possible source of ore-forming fluids and materials in the Shanggong gold deposit through radiogenic isotope geochemistry study; According to the sulfur-lead-strontium isotope system, $\mathrm{Hu}$ Xinlu and other scholars [11] believe that the metallogenic material of Shanggong gold deposit comes from the mixture of mantle and Taihua Group. During the rising process of mantle-derived fluids, some mineralizing materials in the Taihua Group were extracted; According to the theory of mantle branch structure, Song Kai and other scholars [12] believe that the source of ore-forming material of Shanggong gold deposit is mainly deep source (probably core-mantle boundary), supplemented by wall rock extraction. With regard to Ganshu gold deposit, some scholars have shown that the ore-forming materials of the deposit mainly come from deep through isotope geochemical studies [13]; Other scholars have shown that the ore-forming fluid of Ganshu gold deposit may originate from magmatic hydrothermal solution through fluid inclusion and stable isotope geochemistry studies, which is related to the later stage hydrothermal solution of type I granite magma [14].

However, the research results of the above deposits show that there are divergent opinions on the origin of ore-forming materials of these deposits, and the understanding of the genesis of Xiaochigou gold deposit is only of reference value, not of specific guiding significance. Therefore, it is of great practical significance to study the geochemical characteristics of sulfur and lead isotopes in Xiaochigou gold deposit, to explore the source of ore-forming materials, to further analyze ore-controlling factors, to determine ore-forming geological bodies, to establish prospecting model of the deposit, and finally to guide the deep prospecting of the gold deposit.

\section{Mining Area and Deposit Geology}

The outcropped strata in the mining area are the Shibangou Formation $\left(\mathrm{Ar}_{3} \mathrm{sh}\right)$ of the Taihua (Yan) Group, Neoarchean (see Figure 1), which is a set of amphibolite facies metamorphic complex. The lithology is mainly plagioclase amphibolite gneiss, plagioclase amphibolite with biotite plagioclase gneiss lens, etc.

Magmatic activity is intense in the mining area, mainly in the late Yanshanian period. The outcropped rocks are mainly the Jinshanmiao granite in the north and the Sanguanmiao granite in the southeast. The former is mainly composed of biotite monzonitic granite, while the latter is mainly composed of light flesh red medium coarse grained porphyry amphibolite-bearing biotite monzonitic granite.

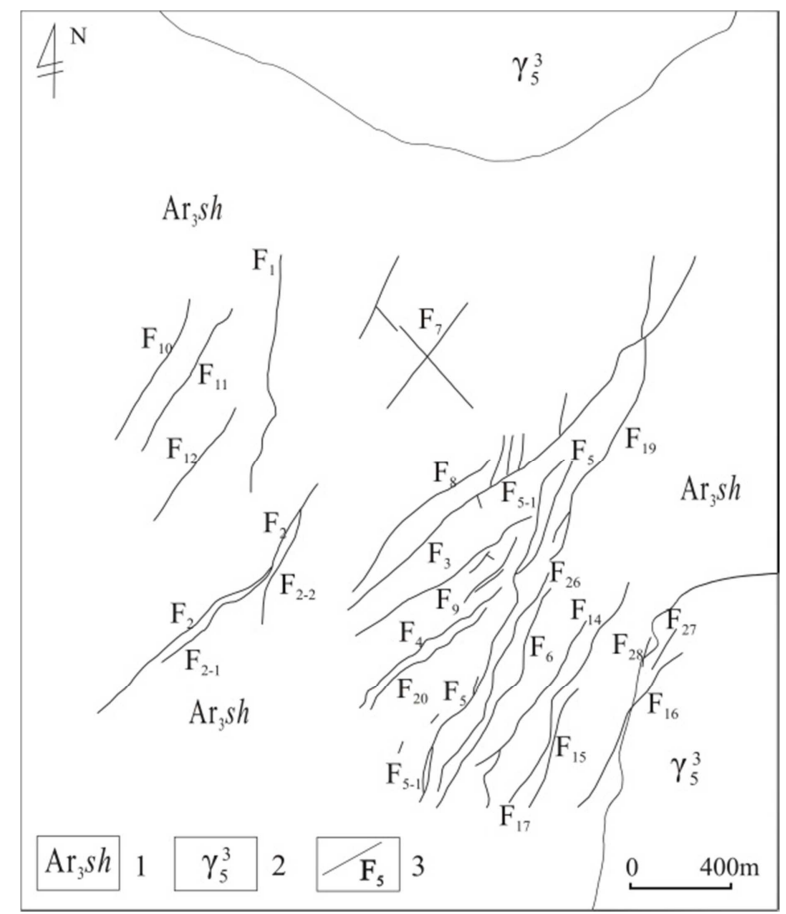

Figure 1. Geological sketch of Xiaochigou Gold Mining Area.

1-Shibangou Formation of Taihua (Yan) Group, Neoarchean, 2-Late Yanshanian granitoids, 3-Mineralization Alteration Zone and Number.

The faults in the mining area are developed mainly in NE, NNE and NW directions. The NE-NNE trending faults are the most developed, and more than 20 faults have been found. Among them, F2, F3, F4, F5, F6 and F19 are large-scale, gently wavy in strike, with branch compound, swelling and shrinking phenomenon, which are the main ore-controlling and ore-hosting structures in the area.

At present, six gold orebodies have been circled in NE-NNE trending faults. The orebody is 130-2 $200 \mathrm{~m}$ long and 0.4-5.0 $\mathrm{m}$ wide. Orebody orientation is NW and SE, NW orientation is $275^{\circ}-320^{\circ}$ and dip angle is $50^{\circ}-81^{\circ}$ and $\mathrm{SE}$ orientation is $109^{\circ}-140^{\circ}$ and dip angle is $50^{\circ}-70^{\circ}$. Gold grade is generally $2.95 \times 10^{-6}-5.1210^{-6}$.

The main ore type is pyrite altered rock type, followed by quartz vein type. The main metal minerals in the ore are pyrite, natural gold, a small amount of galena and chalcopyrite. Gangue minerals include feldspar, quartz, chlorite, kaolin and calcite. Alteration and development of wall rocks mainly include chloritization, sericitization, kaolinization, silicification and pyritization, among which silicification and pyritization are most closely related to mineralization.

According to the vein-like ore body interpenetration relationship and the characteristics of mineral symbiotic assemblage, the mineralization process of Xiaochigou gold deposit can be roughly divided into three stages: (1) medium-coarse pyrite-quartz stage, mainly forming quartz and medium-coarse pyrite; (2) quartz-fine pyrite stage, which is the main mineralization stage, forming a large number of fine-grained pyrite, a small amount of galena and chalcopyrite; (3) fluorite-calcite stage, which is characterized by the presence of calcite veins and a small amount of fluorite veins, 
which marks the end of hydrothermal activity.

\section{Sample Collection and Testing}

\subsection{Sample Collection and Test Method}

The samples used for sulfur and lead isotope testing were collected from quartz-fine pyrite phase ores of F5 and F5-1 veins. Among them, 30 sulfur isotope samples and 10 lead isotope samples were tested. The ore samples were crushed to 40 mesh to 80 mesh, and the metallic sulfide pyrite was selected under binoculars. The purity of the pyrite was above $98 \%$, and then grinded below 200 mesh. The sulfur isotope test was completed in the State Key Laboratory of Environmental Geochemistry, Institute of Geochemistry, Chinese Academy of Sciences. The sulfur isotope was determined by continuous flow isotope mass spectrometer-IsoPrime (model Euro 3000, GV instruments). The analytical accuracy was higher than $(+0.2)$ using VCDT international standard. The lead isotope test was completed by the Analytical and Testing Center of Beijing Institute of Geology, Nuclear Industry. The instrument was IsoProbe-T Thermal Ionization Solid Isotope Mass Spectrometer. The measurement accuracy was less than $0.005 \%$.

\subsection{Test Results}

The sulfur isotope composition of ore sulfides in Xiaochigou gold deposit is shown in Table 1 . The $\delta^{34} \mathrm{~S}$ value of ore sulfide samples is -3.05-10.93, with an average value of 4.47 .
The lead isotopic composition of sulfide in ore of Xiaochigou gold deposit is shown in Table 2. Table 2 shows that ${ }^{206} \mathrm{~Pb} /{ }^{204} \mathrm{~Pb}$ values range from 17.09 to $17.53,{ }^{207} \mathrm{~Pb} /{ }^{204} \mathrm{~Pb}$ values range from 15.31 to 15.61 , and ${ }^{208} \mathrm{~Pb} /{ }^{204} \mathrm{~Pb}$ values range from 37.20 to 38.10 , showing that they have the characteristics of normal lead isotopes.

\section{Discussion}

\subsection{Source of Sulfur}

The sulfides in the ore of Xiaochigou gold deposit are mainly pyrite, galena and chalcopyrite are few, and sulfate minerals are not found. This indicates that sulfur in ore-forming hydrothermal solution mainly exists in the form of $\mathrm{S}^{2-}$, HS-[15]. Therefore, the sulfur isotope composition of pyrite in ore can basically represent the total sulfur isotope composition of ore-forming hydrothermal solution.

The sulfur isotope test results of ore sulfides in Xiaochigou gold deposit show that the sulfur isotope composition ranges from -3.05 to 10.93 (see table 1), most of which are characterized by small positive values (see figure 2 ).

Deines P. et al. [16] suggest that the sulfur from mantle origin has the sulfur isotope composition of meteorite sulfur iron, which varies near 0 . The larger variation range of the value of $\delta^{34} \mathrm{~S}$ is related to the composition of recycled crust, which varies from -6 to 6 .

From Figure 2, it can be seen that the sulfide isotope of Xiaochigou gold deposit has a narrow range of variation.

Table 1. Sulfur isotope composition of ore sulfides in Xiaochigou gold deposit.

\begin{tabular}{|c|c|c|c|}
\hline Sample number & Metallogenic stage & Testing minerals & $\delta^{34} \mathrm{~S} / \% \mathrm{o}$ \\
\hline $\mathrm{XC}-\mathrm{TZ}-1$ & Quartz-fine pyrite & Pyrite & 4.31 \\
\hline XC -TZ -2 & Quartz-fine pyrite & Pyrite & 3.75 \\
\hline $\mathrm{XC}-\mathrm{TZ}-3$ & Quartz-fine pyrite & Pyrite & -3.05 \\
\hline $\mathrm{XC}-\mathrm{TZ}-4$ & Quartz-fine pyrite & Pyrite & 3.99 \\
\hline $\mathrm{XC}-\mathrm{TZ}-5$ & Quartz-fine pyrite & Pyrite & 2.34 \\
\hline XC - TZ-6 & Quartz-fine pyrite & Pyrite & 2.46 \\
\hline $\mathrm{XC}-\mathrm{TZ}-7$ & Quartz-fine pyrite & Pyrite & 3.17 \\
\hline XC - TZ-8 & Quartz-fine pyrite & Pyrite & 10.13 \\
\hline XC - TZ-9 & Quartz-fine pyrite & Pyrite & 4.95 \\
\hline $\mathrm{XC}-\mathrm{TZ}-10$ & Quartz-fine pyrite & Pyrite & 4.34 \\
\hline XC - TZ-11 & Quartz-fine pyrite & Pyrite & 4.26 \\
\hline $\mathrm{XC}-\mathrm{TZ}-12$ & Quartz-fine pyrite & Pyrite & 3.17 \\
\hline $\mathrm{XC}-\mathrm{TZ}-13$ & Quartz-fine pyrite & Pyrite & 2.78 \\
\hline $\mathrm{XC}-\mathrm{TZ}-14$ & Quartz-fine pyrite & Pyrite & 2.7 \\
\hline $\mathrm{XC}-\mathrm{TZ}-15$ & Quartz-fine pyrite & Pyrite & 10.71 \\
\hline $\mathrm{XC}-\mathrm{TZ}-16$ & Quartz-fine pyrite & Pyrite & 10.93 \\
\hline $\mathrm{XC}-\mathrm{TZ}-17$ & Quartz-fine pyrite & Pyrite & 7.72 \\
\hline XC - TZ-18 & Quartz-fine pyrite & Pyrite & 7.9 \\
\hline XC - TZ-19 & Quartz-fine pyrite & Pyrite & 3.25 \\
\hline $\mathrm{XC}-\mathrm{TZ}-20$ & Quartz-fine pyrite & Pyrite & 2.66 \\
\hline $\mathrm{XC}-\mathrm{TZ}-21$ & Quartz-fine pyrite & Pyrite & 3.51 \\
\hline $\mathrm{XC}-\mathrm{TZ}-22$ & Quartz-fine pyrite & Pyrite & 2.04 \\
\hline $\mathrm{XC}-\mathrm{TZ}-23$ & Quartz-fine pyrite & Pyrite & 1.31 \\
\hline XC - TZ-24 & Quartz-fine pyrite & Pyrite & 1.98 \\
\hline $\mathrm{XC}-\mathrm{TZ}-25$ & Quartz-fine pyrite & Pyrite & 4.98 \\
\hline $\mathrm{XC}-\mathrm{TZ}-26$ & Quartz-fine pyrite & Pyrite & 2.75 \\
\hline $\mathrm{XC}-\mathrm{TZ}-27$ & Quartz-fine pyrite & Pyrite & 2.92 \\
\hline $\mathrm{XC}-\mathrm{TZ}-28$ & Quartz-fine pyrite & Pyrite & 10.42 \\
\hline XC - TZ-29 & Quartz-fine pyrite & Pyrite & 3.85 \\
\hline $\mathrm{XC}-\mathrm{TZ}-30$ & Quartz-fine pyrite & Pyrite & 7.78 \\
\hline
\end{tabular}


Table 2. Lead isotope composition and characteristic parameters of sulfide ores in Xiaochigou gold deposit.

\begin{tabular}{|c|c|c|c|c|c|c|c|}
\hline Sample number & Testing minerals & ${ }^{206} \mathrm{~Pb} /{ }^{204} \mathrm{~Pb}$ & ${ }^{207} \mathrm{~Pb} /{ }^{204} \mathrm{~Pb}$ & ${ }^{208} \mathrm{~Pb} /{ }^{204} \mathrm{~Pb}$ & $\mu$ & $\Delta \beta$ & $\Delta \gamma$ \\
\hline XC-TZ-3 & Pyrite & 17.09 & 15.34 & 37.20 & 9.12 & 5.00 & 28.50 \\
\hline XC-TZ-11 & Pyrite & 17.37 & 15.42 & 37.51 & 9.24 & 9.37 & 31.90 \\
\hline XC-TZ-13 & Pyrite & 17.33 & 15.46 & 38.10 & 9.33 & 12.55 & 51.54 \\
\hline XC-TZ-14 & Pyrite & 17.53 & 15.61 & 38.06 & 9.61 & 22.55 & 51.47 \\
\hline XC-TZ-15 & Pyrite & 17.35 & 15.49 & 37.61 & 9.39 & 14.66 & 38.86 \\
\hline XC-TZ-16 & Pyrite & 17.46 & 15.51 & 37.48 & 9.41 & 15.53 & 32.72 \\
\hline XC-TZ-23 & Pyrite & 17.13 & 15.34 & 37.36 & 9.12 & 4.76 & 31.54 \\
\hline XC-TZ-26 & Pyrite & 17.25 & 15.43 & 37.63 & 9.28 & 10.77 & 39.64 \\
\hline XC-TZ-28 & Pyrite & 17.15 & 15.47 & 37.47 & 9.39 & 14.37 & 40.55 \\
\hline XC-TZ-29 & Pyrite & 17.16 & 15.31 & 37.26 & 9.05 & 2.37 & 26.25 \\
\hline
\end{tabular}

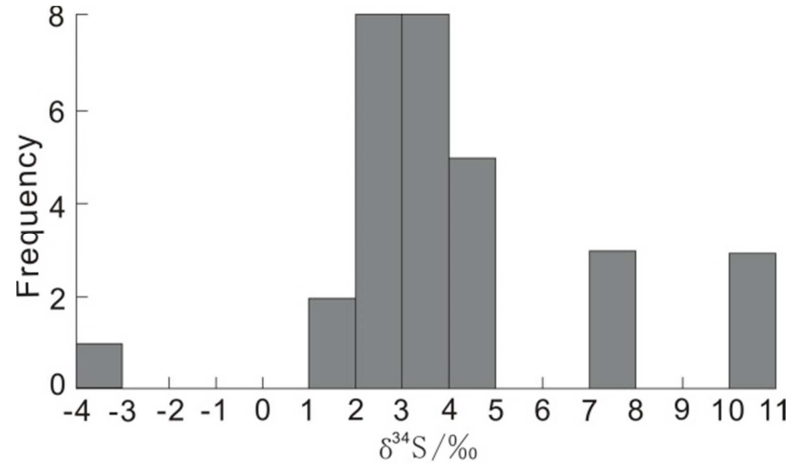

Figure 2. Histogram of sulfur isotope composition of Xiaochigou gold deposit.

and shows an obvious positive peak with a peak value of $1 \sim 5$, which is relatively rich in heavy sulfur, and shows a relatively obvious tower effect, indicating that the sulfur isotope homogenization is relatively high during the mineralization process. The average sulfur isotope composition is 4.47 , which deviates from the range of sulfur in meteorites, and most of the values of $\delta^{34} \mathrm{~S}$ are located in the range of sulfur variation in the mantle. It can be inferred that sulfur in ore-forming fluids of Xiaochigou gold deposit is not a single source, but may be mixed sulfur from multiple sources. Based on the regional geological characteristics and tectonic evolution, it is inferred that the sulfur in ore-forming fluid of Xiaochigou gold deposit mainly comes from the deep part of the earth, which represents the sulfur isotope composition of mantle sulfur mixed with crustal material.

\subsection{Source of Lead}

Wen Chunqi et al. [17] believed that the variation of lead isotope $\mu$ value could provide information about geological processes experienced by geological bodies and reflect the source of lead. $\mu<9.58$ indicates that lead mainly comes from the mantle, and $\mu>9.58$ indicates that lead mainly comes from the upper crust where $U$ and $T h$ are relatively enriched. Table 2 shows that the variation range of lead isotope $\mu$ value of ore sulfides in Xiaochigou gold deposit is 9.05-9.61, with an average value of 9.29 , lower than 9.58 . Only one value is slightly higher than 9.58 and 9.61, indicating that the lead of metal sulfides in Xiaochigou gold deposit mainly comes from the mantle and is contaminated by upper crustal materials.

From the lead tectonic model map of Xiaochigou gold deposit (see Figure 3), it can be seen that in Figure 3-a, the lead isotope data points mainly fall between the lead evolution lines of the mantle and orogenic belt, a small number of data points fall between the lead evolution lines of the mantle and lower crust, and individual data points are between the lead evolution lines of the orogenic belt and the upper crust, and close to the lead evolution lines of the orogenic belt. In Figure $3-b$, the lead isotope data points fall between the orogenic belt and the lower crustal lead evolution line, and tend to the lower crustal lead evolution line. Therefore, the source of lead in Xiaochigou gold deposit is characterized by crust-mantle mixing.
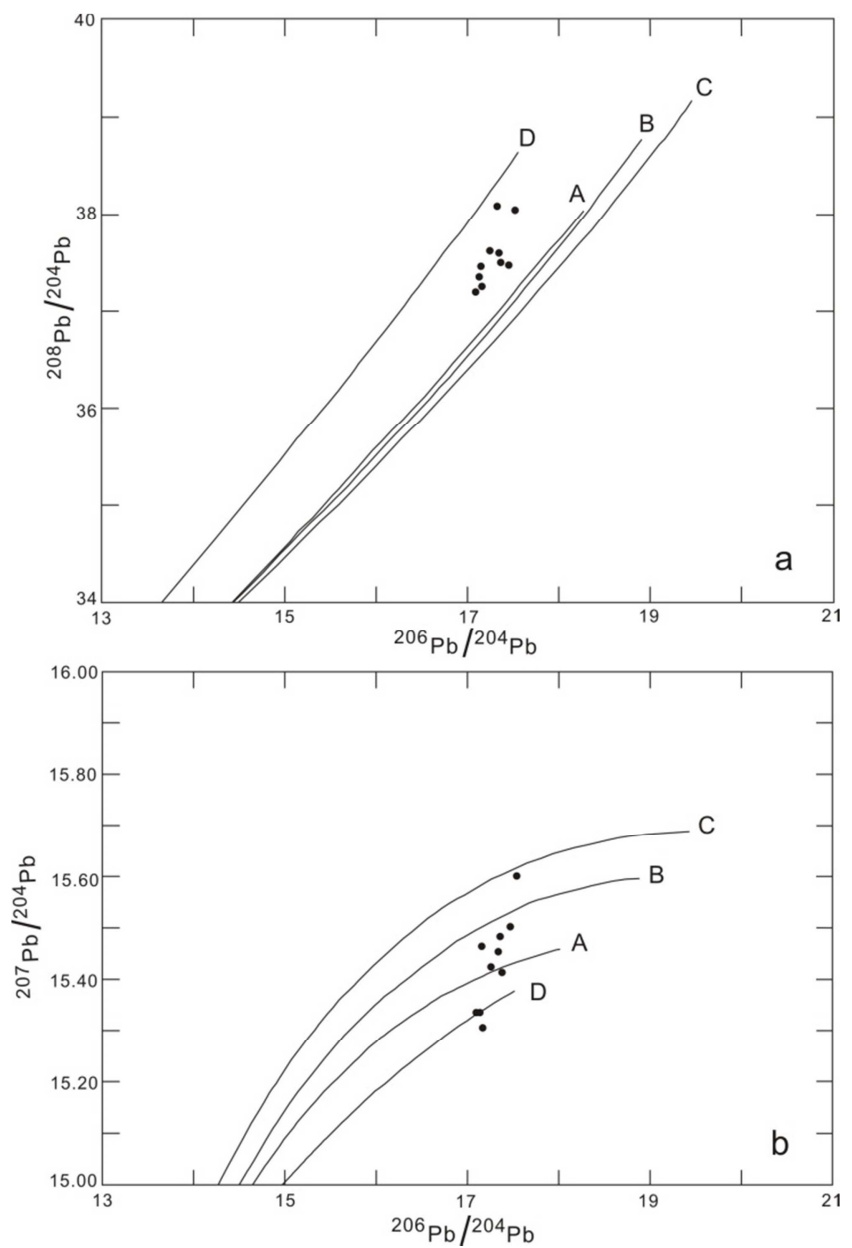

Figure 3. Lead tectonic model map of Xiaochigou gold deposit (the base chart according to document [18]). 
Zhu Bingquan et al. [19] considered that lead isotope parameters $\Delta \beta, \Delta \gamma$ could eliminate the influence of time, and the effect of lead isotope tracing was better. The calculated lead isotopes $\beta$ and $\gamma$ of Xiaochigou gold deposit are 2.37-22.55 and 26.25-51.54 respectively (see Table 2). In the genetic classification diagram of lead isotope $\Delta \beta-\Delta \gamma$ (see Figure 4), projection points are mainly distributed in the lead area of orogenic belt, and individual projection points are located in the magmatic lead area of subduction zone mixed with upper crust and mantle and the lead area derived from upper crust, which further indicates that the lead in Xiaochigou gold deposit is crust-mantle mixed lead.

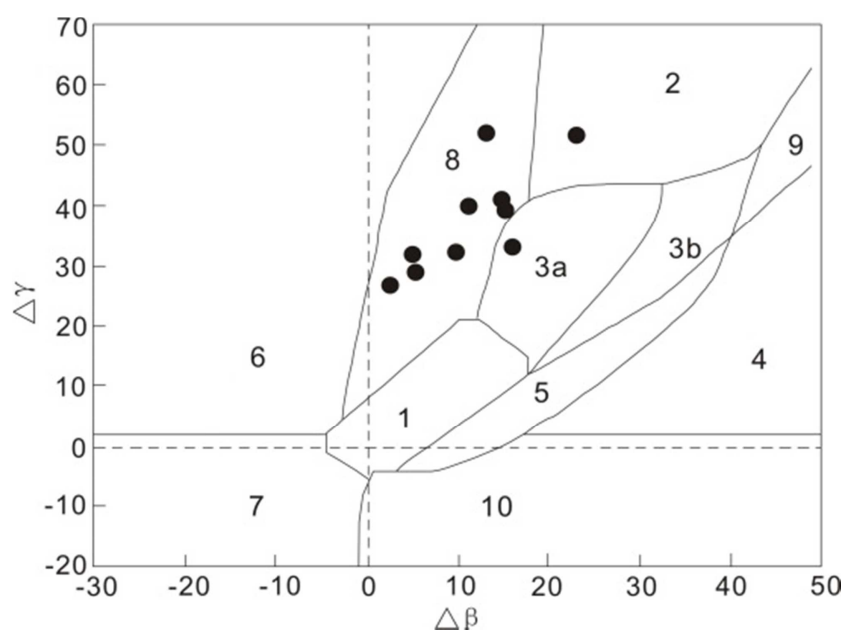

Figure 4. Diagram of genetic classification of lead isotope $\Delta \beta-\Delta \gamma$ in Xiaochigou gold deposit.

1-Mantle-derived Lead, 2-Upper Crustal Source Lead, 3-Lead in Subduction Zone Mixed by Upper Crust and Mantle (3a-Magmatism, 3b-Sedimentation), 4-Chemically Deposited Lead, 5-Submarine hydrothermal lead, 6-Medium-Deep Metamorphic Lead, 7-Deep Metamorphic Lower Crustal Lead, 8-Lead in Orogenic Belt, 9-Lead in the Upper Crust of Ancient Shale, 10-Retrograde lead.

The characteristics of lead isotope composition of Xiaochigou gold deposit indicate that the mineralization is closely related to regional orogeny. During the orogeny, crust-mantle interaction is strong and mantle activity plays an important role. With the continuous orogeny, the mantle fluid carries minerals upward along Qiliping-Xingxingyin regional fault and participates in the mineralization.

The characteristics of lead isotope composition of Xiaochigou gold deposit indicate that the mineralization is closely related to regional orogeny. During the orogeny, crust-mantle interaction is strong and mantle activity plays an important role. With the continuous orogeny, the mantle fluid carries minerals upward along Qiliping-Xingxingyin regional fault and participates in the mineralization.

\section{Conclusion}

1) The sulfur isotope composition of ore sulfides in Xiaochigou gold deposit shows that the sulfur isotope composition of ore is relatively single, most of which are characterized by small positive values. The sulfur in ore-forming hydrothermal solution mainly comes from the mantle, and crustal sulfur is added.

2) The lead isotope composition of sulfide in Xiaochigou gold deposit indicates that lead in ore belongs to normal lead, mainly from the mantle, and is contaminated by lead from crust to different extent, which shows the characteristics of crust-mantle mixing.

3) Based on the study of sulfur and lead isotope geochemical characteristics of Xiaochigou gold deposit and regional metallogenic geological background, it is considered that the ore-forming material of Xiaochigou gold deposit is mainly mantle-derived, with the addition of crustal-derived materials, and has the characteristics of deep mantle-derived materials mixed with crustal-derived materials.

\section{Foundation Project}

Land and Resources Research Project of Henan Province (Land Information Letter of Henan [2017] 237-02).

\section{References}

[1] Li Guoping, Guo Baojian, Li Yongfeng. Spatial distribution regularities of the Xiaochigou vein-type gold deposit, Henan [J]. Mineral Exploration, 2012, 3 (6): 795-803.

[2] Yao Gaiwei. Prospect Analysis of Deep Prospecting in Xiaochigou Gold Mine Area [J]. Modern Mining, 2013 (5): 51-53.

[3] Hu Shouxi, Lin Qianlong, Chen Zeming, et al. Geology and metallogenesis of the North China-South China ancient plate assemblage [M]. Nanjing University Press, 1998, 558.

[4] Chen Yanjing, Fu Shigu. Metallogenic regularity of gold deposits in Western Henan [M]. Beijing: Seismological Press, 1992, 234.

[5] Fan Hongrui, Xie Yihan, Wang Yinglan. Fluid-rock Interaction during Mineralization of the Shanggong structure-controlled alteration-type gold deposit in Western Henan Province, Central China [J]. Journal of Petrology, 1998, 14: 529-541.

[6] Li Shimei, Qu Lunquan, Li Xianmin, et al. Metallogenic regularity and conditions of Xiongershan structure-controlled alteration-type gold deposit. Geology and metallogenesis of the southern margin of the North China Platform [M]. Wuhan: China University of Geology Press, 1996, 161-189.

[7] Kerrich R, Goldfarb R J, Groves D I, et al. The characteristics, origins and geodynamic settings of supergiant gold metallogenicprovinces [J]. Sci. China Ser. D, 2000, 43 (supp): $1-68$.

[8] Hagemann S G, Cassidy K F. Archean orogenic lode gold deposits [J]. SEG Reviews, 2000, 13: 9-68.

[9] Chen Yanjing, Tang Guojun, Franco PIRAJNO, et al. Hydrothermal Metallogeny of the Shanggong Gold Deposit, East Qinling: Radiogenic Isotope Geochemistry [J]. Mineral Rocks, 2004, 24 (3): 22-27.

[10] Wang Xiaohui. Geological characteristics and genesis of Shanggong gold deposit in Luoning county, Henan [J]. Mineral Exploration, 2015, 6 (3): 262-267. 
[11] $\mathrm{Hu}$ Xinlu, He Mouchun, Yao Shuzhen. New Understanding of the Source of Ore-Forming Material and Fluid in the Shanggong Gold Deposit, East Qinling [J]. Journal of Geology, 2013, 87 (1): 91-100.

[12] Song Kai, Hao Xiaoyuan, Wang Jianghe, et al. Discussion on the Ore-controlling Structure and Mineralization Characteristics of Shanggong Gold Deposit in Western Henan Province [J]. Gold Science and Technology, 2013, 21 (6): 30-35.

[13] Hao Xiaoyuan, Songkai, Niu shuyin, et al. The characteristics of wall rock alteration and mineralization of the Ganshu gold deposit in Xionger mountain area, Henan province [J]. Geological prospecting theory cluster, 2015, 30 (1): 75-80.

[14] Feng Shaoping, Wang Jianghe, Deng Hongling, et al. Study of fluid inclusions and stable isotope geochemistry of the Ganshu gold deposit in the Xiong'ershan region [J]. Geochemistry, 2017, 46 (2): 137-148. 137-148.

[15] OНMOTO H. Systematics of sulfur and carbon isotopes in hydrother-mal ore deposits [J]. Economic Geology, 1972, 67: 551-578.

[16] DEINES P, HARRIS J W. Sulfids inclusion chemistry and carbon isotopes of Africa diamonds [J]. Geochimica et Cosmochimica Acta, 1995, 59 (15): 3 173-3 188.
[17] Wen Chunqi, Duoji. Method of ore deposit studies [M]. Chengdu: Sichuan Science and Technology Press, 2009: 170-174.

[18] ZARTMAN R. E, DOE B R. Plumbotectonics-the model [J]. Tectonophysics, 1981, 75 (1/2): 135-162.

[19] Zhu Bingquan, Li Xianhua, Dai Weimo, et al. Theory and application of isotope systems in Geosciences-Concurrently on the evolution of crust and mantle in China mainland [M]. Beijing: Science Press, 1998: 224-226.

\section{Biography}

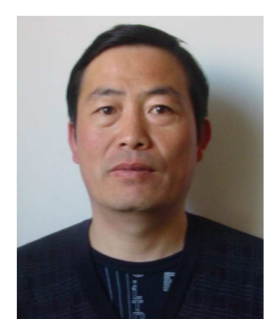

Liu Zhenghua (1968-), male, from Qixian County, Henan Province, a senior engineer engaged in exploration and research of non-ferrous metals; Block A, Henan Geological and Mineral Science and Technology Industrial Park, Fengqi Street, Zhengdong New District, Zhengzhou City, Henan Nonferrous Mineral Exploration Engineering Research Center. 